\title{
THE DISSOCIATION CONSTANT OF AMMONIUM NITRATE AND ITS DEPENDENCE ON TEMPERATURE, RELATIVE HUMIDITY AND PARTICLE SIZE
}

\author{
Michael Mozurkewich \\ Department of Chemistry, York Univervity, 4700 Keele Street, North York, Ontario, Canada M3J IP3
}

\begin{abstract}
Aletrect-The diseociation constant of $\mathrm{NH}_{4} \mathrm{NO}_{3}(c, I V)$ is determised from the evaluntion of literature data from a variety of sources. Throe diferent methode of calculation using five independent dats wets lead to accurate values of the dimociation constant; these are in excellent acroement with each other. The recommended value of the atandard tree eneryy of diesociation of $\mathrm{NH}_{4} \mathrm{NO}_{3}(c, I V)$ to $\mathrm{NH}_{3}(\sigma)$ and $\mathrm{HNO}_{3}(8)$ is $93.4 \pm 0.3 \mathrm{~kJ} \mathrm{~mol}^{-1}$. Over the temperature range for which crystalline phase IV is etable $\left(-17\right.$ to $32^{\circ} \mathrm{C}$, the temperature dependence of the diseociation constant (in units of $\mathrm{nb}^{2}$ ) is eiven to within $\pm 12 \%$ by
\end{abstract}

$$
\ln \left(K_{p}\right)=118.87-\frac{24084}{T}-6.025 \ln (T)
$$

Equations are also given for the computation of the diwociation constant of $\mathrm{NH}_{4} \mathrm{NO}_{3}(\mathrm{aq})$ to $\mathrm{NH}_{3}(\mathrm{~g})$ and $\mathrm{HNO}$ (s) as a function of temperature and either solution concentration or equilibrium relative humidity. For saturnted solutions these equations are consintent with the results for the solid, and for dilute solutions they are consintent with data on dilute solutions of $\mathrm{NH}_{3}(\mathrm{aq})$ and $\mathrm{HNO}_{3}(\mathrm{aq})$. For particles with radii kes than $0.1 \mathrm{\mu m}$, the Kelvin effect has a subutantial effect on the disecciation constant. However, particle size has little effect on the deliquescence point.

Key word index: Distociation constant, ammonium nitrate, gas-particle exchange, aerosol equilibria.

\section{INTRODUCTION}

$\mathrm{NH}_{4} \mathrm{NO}_{3}$ is often a significant component of atmospheric particles in polluted areas. If $\mathrm{NH}_{3}$ and $\mathrm{HNO}_{3}$ can exchange readily between the gas and particle phases then an equilibrium should exist between atmospheric $\mathrm{NH}_{4} \mathrm{NO}_{3}(\mathrm{~s}), \mathrm{NH}_{3}(\mathrm{~g})$ and $\mathrm{HNO}_{3}(\mathrm{~g})$. The ges-phase concentrations of $\mathrm{NH}_{3}$ and $\mathrm{HNO}_{3}$ would then be limited by this equilibrium. Furthermore, the rate of evaporation of $\mathrm{NH}_{4} \mathrm{NO}_{3}$ from particles should depend on its diesociation (or solid-vapour equilibrium) constant. The evaporation rate affects the dry deposition of $\mathrm{NH}_{3}$ and $\mathrm{HNO}_{3}$ since the deposition velocities depend upon whether these species are in the gas or particle phase (Huebert et al., 1988; Brost et al. 1988). Possible artifacts in measuring $\mathrm{NH}_{3}$ and $\mathrm{HNO}_{3}$ also depend on the rate of gas-particle exchange (Durham et al., 1987). The interpretation of experimental measurements of this evaporation rate (Harrison et al., 1990) also requires a knowledge of the equilibrium constant.

Values of the $\mathrm{NH}_{3} \mathrm{NO}_{3}$ dissociation constant that appear in the atmospheric chemistry literature vary by about a factor of two. Stelson and Seinfeld (1982) recommended a value for the equilibrium constant (at $298.15 \mathrm{~K}$ ) of $30 \mathrm{nb}^{2}$; this was based on tabulated thermodynamic data. Stelson et al. (1979) arrived at a value of $41 \mathrm{ab}^{2}$ from slightly different thermodynamic data and a value of $54 \mathrm{nb}^{2}$ from extrapolating the vapour pressure data of Brandner et al. (1962).
Wexler and Seinfeld (1991) use tabulated data to arrive at a value of $59 \mathrm{ab}^{2}$. These dissociation constants correspond to standard free energies of dissociation, $\Delta G_{\text {din }}^{\circ}$ (a standard state of 1 b at $298.15 \mathrm{~K}$ will be used here), of $94.3,93.5,92.8$ and $92.6 \mathrm{~kJ} \mathrm{~mol}^{-1}$, respectively.

Several studies of atmosphere concentrations of $\mathrm{NH}_{3}(\mathrm{~g})$ and $\mathrm{HNO}_{3}(\mathrm{~g})$ have been made (Stelson et al., 1979; Allen et al., 1989, and references therein). When sufficient $\mathrm{NH}_{3}(0)$ and $\mathrm{HNO}_{3}(\mathrm{O})$ are present at temperatures above $5^{\circ} \mathrm{C}$, the product of the partial pressures was found to be in rough agreement with the $\mathrm{NH}_{4} \mathrm{NO}_{3}$ dissociation constants recommended by Stelson et al. (1979) and consistently somewhat larger than the values rocommended by Steleon and Seinfeld (1982). At lower temperatures the partial pressures tend to be considerably higher than expected from the diseociation constant; this has been attributed to kinetic factors (Harrison and MacKenrie, 1990; Wexler and Seinfeld, 1992).

Jafie (1988) has questioned the validity of the recommended dissociation constants. He argued that the thermodynamic data are probably based on the vapour pressure measurements and that the extrapolation of the vapour pressure measurements over a wide temperature range could result in errors of more than an order of magnitude in the dissociation constant. If this constant is indeed off by this much, the atmospheric measurements of $\mathrm{NH}_{3}(\mathrm{~g})$ and $\mathrm{HNO}_{3}(\mathrm{~g})$ cited above would have to be reinterpreted 
and the effect of gas-particle exchange on dry deposition and on measurements of gas-phase concentrations would have to be reassessed.

In fact, the available thermodynamic data on this system is much better than is implied by the factor of two range implied by the work cited above. It will be shown in the following that the dissociation constant, $K_{\mathrm{p}}$, may be determined to within $\pm 12 \%$. Values of $\Delta G_{\text {diss }}^{0}$ and $K_{p}(298)$, derived from several independent sets of measurements, are summarized in Table 1 and discussed individually in the following.

\section{EXTRAPOLATION OF VAPOUR PRESSURE MEASUREMENTS}

Feick (1954) has measured the vapour pressure of liquid $\mathrm{NH}_{4} \mathrm{NO}_{3}$ and Brandner et al. (1962) have measured the vapour pressure of solid and liquid $\mathrm{NH}_{4} \mathrm{NO}_{3}$ at elevated temperatures. Jaffe (1988) has criticized the extrapolation of this data to lower temperatures, largely because of the sensitivity of the extrapolation to small changes in the slope or intercept. Such errors come from two sources. First, in fitting the data to obtain the entropy and enthalpy of vaporization, each parameter can partially compensate for errors in the other. Errors in the experimental measurement then become magnified in the extrapolation. Second, the enthalpy and entropy of vaporization are themselves functions of temperature. If this is not accounted for in the extrapolation, the results will not be reliable. Jaffe also mentions several possible sources of systematic error in the experiments of Brandner et al. (1962). It should be noted that Brandner et al. (1962) took steps to avoid these errors.

Errors due to the temperature dependence of the enthalpies and entropies can be essentially eliminated by using heat capacity and enthalpy of phase transition data. Furthermore, if these data are available to a sufficiently low temperature then the absolute entropy change of the reaction may be determined. This eliminates the first source of error described above. In effect, a determination of the dissociation constant at any one temperature becomes a measurement of $\Delta G_{\text {diss }}^{0}$. When vapour pres- sure measurements are available over a range of temperatures they constitute a set of replicate measurements of this one quantity.

Accurate thermodynamic data for $\mathrm{NH}_{3}, \mathrm{HNO}_{3}$ and $\mathrm{NH}_{4} \mathrm{NO}_{3}$ over the required temperature range are available in the literature. For $\mathrm{NH}_{4} \mathrm{NO}_{3}$, Stephenson et al. (1955) and Nagatani et al. (1967) report low temperature heat capacity and enthalpy of transition data that are in excellent agreement with each other. Eichenauer and Liebscher (1965) report data that differ somewhat, especially in the value of the entropy at $298 \mathrm{~K}$. Nagatani et al. (1967) attribute the discrepancy to an incomplete phase transition. For the calculations presented here, I will use the data of Nagatani et al. (1967) since it extends to the highest temperature, $410 \mathrm{~K}$, and appears to be the most thorough study. For calculations above $410 \mathrm{~K}$, I have extrapolated Nagatani et al.'s (1967) heat capacity data for crystalline phase I to the melting point at 442.75 K (Dellien, 1982), used the value of the heat of fusion of $6.20 \pm 0.20 \mathrm{~kJ} \mathrm{~mol}^{-1}$ reported by Dellien (1982), and used the liquid phase heat capacity (0.191 J mol ${ }^{-1} \mathrm{~K}^{-1}$ ) measured by Feick (1954). Data for $\mathrm{NH}_{3}(\mathrm{~g})$ were taken from Haar (1968) while data for $\mathrm{HNO}_{3}(\mathrm{~g})$ were taken from the JANAF tables (Chase et al., 1985).

The standard free energy of dissociation was determined from two sets of vapour pressure measurements; those of Feick (1954) over the liquid at 442.8-522.3 K and those of Brandner et al. (1962) over the solid at $349.2-438.2 \mathrm{~K}$ and over the liquid at 443.2-513.2 K. Each reported vapour pressure was used to determine the dissociation constant at that temperature from the formula $K_{\mathrm{p}}=\left(P_{\text {vap }} / 2\right)^{2}$. These were then used to compute $\Delta G_{\text {diss }}^{\circ}$ at $298.15 \mathrm{~K}$ using the tabulated thermodynamic data. The individual data points are plotted in Fig. 1; the agreement between these points is good. Since the two data sets agree well an average of all the points was taken; this average is reported in Table 1; error limits were estimated as twice the standard error of the mean. The actual uncertainty should be somewhat larger due to possible systematic errors in the measurements and uncertainties in the data used to adjust the values to $298 \mathrm{~K}$. The resulting value of $K_{\mathrm{p}}(298)$ is only slightly larger than that recommended by Stelson et al. (1979).

Table 1. Values of the standard Gibbs free energy of dissociation and the dissociation constant at $298.15 \mathrm{~K}$

\begin{tabular}{|c|c|c|c|c|}
\hline \multirow[b]{2}{*}{ Method } & \multicolumn{2}{|c|}{$\begin{array}{c}S^{\circ} \text { from Nagatani et al. } \\
(1967)\end{array}$} & \multicolumn{2}{|c|}{$\begin{array}{l}S^{\circ} \text { from Eichenauer and } \\
\text { Liebscher (1965) }\end{array}$} \\
\hline & $\begin{array}{c}\Delta G_{\mathrm{diss}}^{\mathrm{o}} \\
\left(\mathrm{kJ} \mathrm{mol}^{-1}\right)\end{array}$ & $\begin{array}{c}K_{\mathrm{p}} \\
\left(n b^{-2}\right)\end{array}$ & $\begin{array}{c}\Delta G_{\text {diss }}^{\mathrm{o}} \\
\left(\mathrm{kJ} \mathrm{mol}^{-1}\right)\end{array}$ & $\begin{array}{c}K_{\mathrm{p}} \\
\left(\mathrm{nb}^{-2}\right)\end{array}$ \\
\hline $\begin{array}{l}\text { Vapour pressure } \\
\text { Vapour-solution equilibria } \\
\text { Calorimetry (heats of formation) } \\
\text { Calorimetry (heats of solution) } \\
\text { Weighted average }\end{array}$ & $\begin{array}{l}93.20 \pm 0.25 \\
93.26 \pm 0.27 \\
94.11 \pm 0.56 \\
93.51 \pm 0.22 \\
93.39\end{array}$ & $\begin{array}{l}47 \pm 5 \\
46 \pm 5 \\
33 \pm 7 \\
41 \pm 4 \\
43\end{array}$ & $\begin{array}{l}93.84 \pm 0.22 \\
93.26 \pm 0.27 \\
92.76 \pm 0.56 \\
92.16 \pm 0.22 \\
93.05\end{array}$ & $\begin{array}{l}36 \pm 3 \\
46 \pm 5 \\
56 \pm 13 \\
71 \pm 6 \\
50\end{array}$ \\
\hline
\end{tabular}




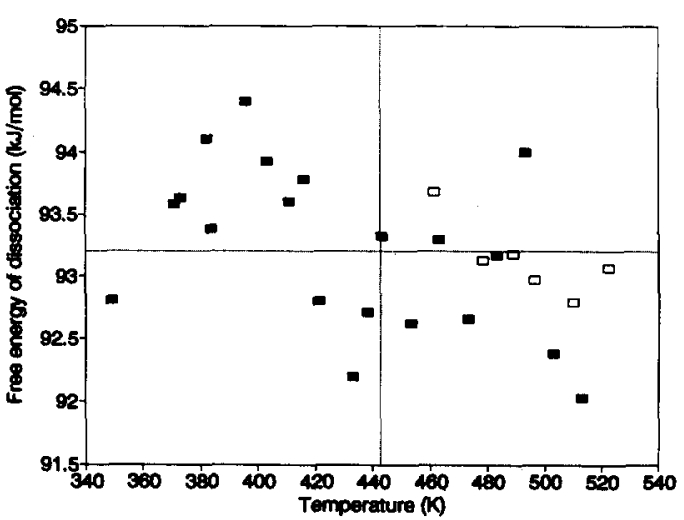

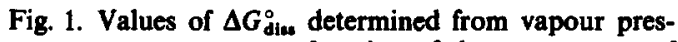
sure measurements as a function of the temperature of the measurement. The horizontal line is the average of all points and the vertical line indicates the melting point of $\mathrm{NH}_{4} \mathrm{NO}_{3}$. Data of Brandner et al. (1962), $\square$ data of Feick (1954).

A close examination of Fig. 1 shows a slight downward trend in $\Delta G_{\mathrm{dim}}^{\mathrm{o}}$ with increasing temperature of the measurement. Although this trend accounts for only about $20 \%$ of the total variance, it is statistically significant at the $95 \%$ confidence level. One possible source of this trend would be an error in the value of $\Delta S_{\mathrm{dim}}^{\mathrm{g}}$ since this would change the temperature dependence of $\Delta G_{\text {diss. }}^{\circ}$ This trend may be almost completely eliminated if the value of $S^{\circ}\left(\mathrm{NH}_{4} \mathrm{NO}_{3}\right)$ reported by Eichenauer and Liebscher (1965) is used instead of the value reported by Nagatani et al. (1967). Table 1 includes values of $\Delta G_{\text {dina }}^{\circ}$ based on both values of $\mathrm{S}^{\circ}\left(\mathrm{NH}_{4} \mathrm{NO}_{3}\right)$.

Additional vapour pressure measurements have been reported by Dionne et al. (1986). These do not appear to be of as high a quality as the earlier measurements. First, Dionne et al. (1986) do not seem to have conducted any tests to ensure that vapour-solid equilibrium was achieved. Also, only the partial pressure of $\mathrm{HNO}_{3}(\mathrm{~g})$ was measured and it is not clear if the reported "vapour pressure" is the total vapour pressure or only this partial pressure. The data were reported in the form of a ClausiusClapeyron equation; the results suggest a dissociation consant that is somewhat smaller, with a weaker temperature dependence, than the other measurements.

de Kruif (1982) has reported vapour effusion results that suggest that $\mathrm{NH}_{4} \mathrm{NO}_{3}$ is only partially dissociated in the gas phase at $352 \mathrm{~K}$. His reported vapour pressure at this temperature agrees with the results of Brandner et al. (1962). However, de Kruif's (1982) data appear to be incorrectly analysed since he did not account for the effect of differing rates of effusion on the vapour-phase concentrations of the various species. When his equations are modified to account for this, the results are no longer physically possible.

\section{CALCULATION OF THE DISSOCIATION CONSTANT FROM VAPOUR-SOLUTION EQUILIBRIA}

For a solution of $\mathrm{NH}_{4} \mathrm{NO}_{3}$ in water, we may define a concentration-dependent dissociation constant, $K_{p}^{*}$, by

$$
K_{\mathrm{p}}^{*}=P\left(\mathrm{NH}_{3}\right) P\left(\mathrm{HNO}_{3}\right),
$$

where $P\left(\mathrm{NH}_{3}\right)$ and $P\left(\mathrm{HNO}_{3}\right)$ are the equilibrium partial pressures of $\mathrm{NH}_{3}$ and $\mathrm{HNO}_{3}$ over the solution. We also note that

$$
P\left(\mathrm{NH}_{3}\right)=\frac{a\left(\mathrm{NH}_{3}\right)}{H\left(\mathrm{NH}_{3}\right)}
$$

and

$$
P\left(\mathrm{HNO}_{3}\right)=\frac{a\left(\mathrm{HNO}_{3}\right)}{H\left(\mathrm{HNO}_{3}\right)},
$$

where $a$ is the activity of the solute and $H$ is the Henry's law constant. As long as activities are used, these expressions are valid for both concentrated and dilute solutions. Similarly, we may express the acid dissociation constants for $\mathrm{NH}_{4}^{+}$and $\mathrm{HNO}_{3}$ as

$$
K_{\mathrm{a}}\left(\mathrm{NH}_{4}^{+}\right)=\frac{a\left(\mathrm{NH}_{3}\right) a\left(\mathrm{H}^{+}\right)}{a\left(\mathrm{NH}_{4}^{+}\right)}
$$

and

$$
K_{2}\left(\mathrm{HNO}_{3}\right)=\frac{a\left(\mathrm{NO}_{3}^{-}\right) a\left(\mathrm{H}^{+}\right)}{a\left(\mathrm{HNO}_{3}\right)} .
$$

Finally, we note that for a solution of $\mathrm{NH}_{4} \mathrm{NO}_{3}$ in water

$$
a\left(\mathrm{NH}_{4}^{+}\right) a\left(\mathrm{NO}_{3}^{+}\right)=\left(\gamma_{ \pm} m\right)^{2},
$$

where $\gamma_{ \pm}$is the mean activity coefficient and $m$ is the molality of $\mathrm{NH}_{4} \mathrm{NO}_{3}(\mathrm{aq})$. Now Equations (2)-(6) may be substituted into Equation (1) to give

$$
K_{\mathrm{p}}^{*}=\frac{\left(\gamma_{ \pm} m\right)^{2} K_{\mathrm{a}}\left(\mathrm{NH}_{4}^{+}\right)}{K_{\mathrm{a}}\left(\mathrm{HNO}_{3}\right) H\left(\mathrm{HNO}_{3}\right) H\left(\mathrm{NH}_{3}\right)} .
$$

$K_{p}^{*}$ may be related to $K_{\mathrm{p}}$ by

$$
K_{\mathrm{p}}^{*}=\left(\gamma_{ \pm} m\right)^{2} \frac{K_{\mathrm{p}}}{K_{\mathrm{sp}}}
$$

where $K_{\mathrm{ap}}$ is the solubility product constant for $\mathrm{NH}_{4} \mathrm{NO}_{3}(\mathrm{~s})$. For a saturated solution, $K_{\mathrm{sp}}=$ $\left(\gamma_{ \pm \text {,ant }} m_{\text {sat }}\right)^{2}$. Then $K_{\mathrm{p}}^{*}=K_{\mathrm{p}}$; that is, the solution is in equilibrium with the solid and the vapour pressure product is therefore the same as for the solid. Thus, combining (7) and (8) for the saturated solution:

$$
K_{\mathrm{p}}=\frac{\left(\gamma_{t, \mathrm{mat}} m_{\mathrm{ata}}\right)^{2} K_{\mathrm{a}}\left(\mathrm{NH}_{4}^{+}\right)}{K_{\mathrm{a}}\left(\mathrm{HNO}_{3}\right) H\left(\mathrm{HNO}_{3}\right) H\left(\mathrm{NH}_{3}\right)} .
$$

Published data exist for all the quantities on the right-hand side of Equation (9). For a saturated solution, $\gamma_{ \pm, \text {sat }}=0.1317$ and $m_{\text {aat }}=25.954$ molal (Wishaw and Stokes, 1953). The product $K_{\mathrm{a}}\left(\mathrm{HNO}_{3}\right) \mathrm{H}\left(\mathrm{HNO}_{3}\right)$ has a value of $(2.59 \pm 0.20) \times 10^{6} \mathrm{~mol}^{2} \mathrm{~kg}^{-2} \mathrm{~b}^{-1}(\mathrm{Clegg}$ 
and Brimblecombe, 1990; Tang et al., 1988). Dasgupta and Dong (1986) have measured the solubility of $\mathrm{NH}_{3}$ in water over the temperature range $279-291 \mathrm{~K}$ and have corrected the results for the effects of ionic strength and for equilibrium with $\mathrm{NH}_{4}^{+}$. They also provide a discussion of earlier measurements on this system; these other measurements do not seem to be as suitable for a thermodynamic calculation (infinitely dilute solution, zero ionic strength). Extrapolating their results to $298 \mathrm{~K}$ yields $H(\mathrm{NH} 3)=$ $55.3 \pm 4 \mathrm{~mol} \mathrm{~kg}^{-1} \mathrm{~b}^{-1}$. This extrapolation is over a small enough temperature range that $\Delta C_{p}$ may be neglected since its effect on $\Delta H$ and $\Delta S$ will nearly cancel in $\Delta G$. Finally, $K_{\mathrm{a}}\left(\mathrm{NH}_{4}^{+}\right)=$ $5.69 \times 10^{-10} \mathrm{~mol} \mathrm{~kg}^{-1}$ (Bates and Pinching, 1950). Substituting these values into Equation (9) yields $K_{\mathrm{p}}(298)=46.5 \pm 5 \mathrm{nb}^{2}$ and $\Delta G_{\mathrm{diss}}^{\mathrm{o}}=93.2 \pm 0.3 \mathrm{~kJ}$ $\mathrm{mol}^{-1}$

\section{CALORIMETRIC DETERMINATION OF THE FREE ENERGY OF DISSOCIATION}

Standard enthalpies of formation and standard absolute entropies for $\mathrm{NH}_{4} \mathrm{NO}_{3}(\mathrm{c}, \mathrm{IV}), \mathrm{NH}_{3}(\mathrm{~g})$ and $\mathrm{HNO}_{3}(\mathrm{~g})$ have been determined from calorimetric measurements. The values are summarized in Table 2 . The references review earlier measurements. For $\Delta H_{\mathrm{f}}^{\mathrm{o}}\left(\mathrm{HNO}_{3}(\mathrm{~g})\right)$ the value given by Forsythe and Giauque (1942) was used, instead of that in the JANAF tables, since the latter is an average of values from several sources that are neither independent of each other nor of the data used elsewhere in this paper. Combining these data yields $\Delta H_{\text {diss }}^{\circ}=186.00$ $\pm 0.56 \mathrm{~kJ} \mathrm{~mol}^{-1}$. Using the data of Nagatani et al. (1967), $\Delta S_{\text {diss }}^{0}=308.36 \mathrm{~J} \mathrm{~mol}^{-1} \mathrm{~K}^{-1}$, whereas the data of Eichenauer and Liebscher (1965) yield $\Delta S_{\text {diss }}^{o}=312.73 \mathrm{~J} \mathrm{~mol}^{-1} \mathrm{~K}^{-1}$. The resulting values of $\Delta G_{\mathrm{diss}}^{\mathrm{o}}$ are given in Table 1 .

Additional, independent, calorimetric data are available for heats of solution. A cycle, equivalent to the dissociation reaction, may be constructed from the reactions

$$
\begin{gathered}
\mathrm{NH}_{4} \mathrm{NO}_{3}(\mathrm{c}, \mathrm{IV}) \rightarrow \mathrm{NH}_{4}^{+}(\mathrm{aq})+\mathrm{NO}_{3}^{-}(\mathrm{aq}) \\
\mathrm{H}_{2} \mathrm{O}(\mathrm{l}) \rightarrow \mathrm{H}^{+}(\mathrm{aq})+\mathrm{OH}^{-}(\mathrm{aq}) \\
\mathrm{H}^{+}(\mathrm{aq})+\mathrm{NO}_{3}^{-}(\mathrm{aq}) \rightarrow \mathrm{HNO}_{3}(\mathrm{~g}) \\
\mathrm{OH}^{-}(\mathrm{aq})+\mathrm{NH}_{4}^{+}(\mathrm{aq}) \rightarrow \mathrm{NH}_{3}(\mathrm{aq})+\mathrm{H}_{2} \mathrm{O}(\mathrm{l}) \\
\mathrm{NH}_{3}(\mathrm{aq}) \rightarrow \mathrm{NH}_{3}(\mathrm{~g}) .
\end{gathered}
$$

Standard enthalpies of reaction are given in Table 2. The papers by Vanderzee and King (1962) and Vanderzee et al. $(1972,1980 \mathrm{a}, \mathrm{b})$ provide comparisons with earlier results. A comparison of data on $\mathrm{HNO}_{3}$ solubility given by Tang et al. (1988) suggests that the data of Forsythe and Giauque (1942) are not reliable. However, the discrepancies appear to be due to the estimate used for $\mathrm{S}^{\circ}\left(298, \mathrm{NO}_{3}^{-}\right.$, aq) and an arithmetic error in computing $\Delta G$ from $\Delta H$ and $\Delta S$, rather than in the heat of solution. For the dissociation reaction, this cycle yields $\Delta H_{\mathrm{diss}}^{\circ}=185.40 \pm 0.22 \mathrm{~kJ} \mathrm{~mol}^{-1}$. Combining this with the entropy data gives the values of $\Delta G_{\text {diss }}^{\mathbf{o}}$ listed in Table 1 .

\section{RECOMMENDED VALUES OF DISSOCIATION CONSTANT AND FREE ENERGY OF FORMATION}

The results summarized in Table 1 show that when the absolute entropy determined by Nagatani et al. (1967) is used there is excellent agreement among the standard free energies of dissociation of $\mathrm{NH}_{4} \mathrm{NO}_{3}$ (c, IV) as determined by several methods. The value determined from the heat of formation data differs somewhat from the others but it is also the most uncertain. The difference may be due to an error in the value for $\Delta H_{\mathrm{f}}^{\circ}\left(\mathrm{HNO}_{3}(\mathrm{~g})\right)$ given by Forsythe and Giauque (1942). Cox et al. (1989) recommend $\Delta H_{\mathrm{f}}^{\circ}\left(\mathrm{HNO}_{3}(\mathrm{~g})\right)=-134.2 \pm 0.4 \mathrm{~kJ} \mathrm{~mol}^{-1}$; using this value would yield $\Delta G_{\text {diss }}^{\mathrm{a}}=93.75 \mathrm{~kJ} \mathrm{~mol}^{-1}$, in much better agreement with the other measurements. This value was not used in the present analysis since it

\begin{tabular}{|c|c|c|}
\hline Quantity & Value & Reference \\
\hline$\Delta H_{\mathrm{f}}^{\circ}\left(\mathrm{NH}_{4} \mathrm{NO}_{3}(\mathrm{c}, \mathrm{IV})\right)$ & $-365.61 \pm 0.32$ & Cox et al. (1979) \\
\hline$\Delta H_{\mathrm{f}}^{\circ}\left(\mathrm{NH}_{3}(\mathrm{~g})\right)$ & $-45.77 \pm 0.19$ & Vanderzee and King (1972) \\
\hline$\Delta H_{\mathrm{f}}^{\circ}\left(\mathrm{HNO}_{3}(\mathrm{~g})\right)$ & $-133.84 \pm 0.4$ & Forsythe and Giauque (1942) \\
\hline$S^{\circ}\left(\mathrm{NH}_{4} \mathrm{NO}_{3}(\mathrm{c}, \mathrm{IV})\right)$ & 150.81 & Nagatani et al. (1967) \\
\hline$S^{\circ}\left(\mathrm{NH}_{4} \mathrm{NO}_{3}(\mathrm{c}\right.$, IV $\left.)\right)$ & 146.44 & Eichenauer and Liebscher (1965) \\
\hline$S^{\circ}\left(\mathrm{NH}_{3}(\mathrm{~g})\right)$ & 192.77 & Haar (1968) \\
\hline$S^{\circ}\left(\mathrm{HNO}_{3}(\mathrm{~g})\right)$ & 266.40 & Chase et al. (1985) \\
\hline$\Delta H_{\mathrm{rxm}}^{\mathrm{o}}(10)$ & $25.54 \pm 0.03$ & Vanderzee et al. (1980b) \\
\hline$\Delta H_{\mathrm{rnn}}^{0}(11)$ & $55.88 \pm 0.05$ & Pitzer (1937) \\
\hline$\Delta H_{\mathrm{rnn}}^{\mathrm{o}}(12)$ & $72.48 \pm 0.2$ & Forsythe and Giauque (1942) \\
\hline$\Delta H_{\mathrm{rxn}}^{\mathrm{o}}(13)$ & $-3.85 \pm 0.04$ & Vanderzee et al. (1972) \\
\hline$\Delta H_{\mathrm{rxn}}^{\mathrm{o}}(14)$ & $35.35 \pm 0.06$ & Vanderzee and King (1972) \\
\hline
\end{tabular}
relies on much of the data used in the other methods and is therefore not independent of them.

Table 2. Calorimetric data used to determine the standard free energy of dissociation. Enthalpies are in $\mathrm{kJ} \mathrm{mol}^{-1}$, entropies in $\mathrm{J} \mathrm{mol}^{-1} \mathrm{~K}^{-1}$ 
These measurements are independent except that the determinations other than that based on the vapour-solution equilibria all depend on the absolute entropies at $298 \mathrm{~K}$. An error in this quantity would cause the values of $\Delta G_{\text {diss }}^{\circ}$ calculated from the vapour pressure measurements to increase or decrease systematically as the temperature of the measurement changes. Such a trend does occur if the data of Nagatani et al. (1967) are used (Fig. 1) but not if the data of Eichenauer and Liebscher (1965) are used. However, there are several arguments against using the later data. First, as may be seen in Table 1, this data leads to substantial disagreements between the results of the different methods. Second, the data of Nagatani $e t$ al. appear to be of higher quality and are confirmed by the measurements of Stephenson $e t$ al. (1955). Finally, the small trend in Fig. 1 could be due to systematic error in the measurements rather than an error in $\Delta S_{\text {diss }}^{\circ}$.

A weighted average of the values in Table 1 based on the absolute entropy given by Nagatani et al. yields a recommended value of $93.4 \pm 0.3 \mathrm{~kJ} \mathrm{~mol}^{-1}$ for

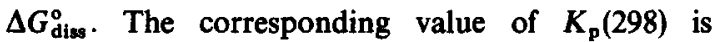
$43 \pm 5 \mathrm{nb}^{2}$ and $\Delta H_{\text {diss }}^{\circ}=185.3 \mathrm{~kJ} \mathrm{~mol}^{-1}$.

\section{TEMPERATURE AND RELATIVE HUMIDITY DEPENDENCE}

At atmospheric pressure, $\mathrm{NH}_{4} \mathrm{NO}_{3}(\mathrm{c}, \mathrm{IV})$ is stable with respect to other crystalline phases over the temperature range 256.2-305.4 K (Dellien, 1982). Over this limited range, the heat capacities may be taken as constant and the dissociation constant may be calculated from the integrated form of the van't Hoff equation:

$$
\begin{aligned}
\ln \left(K_{\mathrm{p}}\right)= & \frac{\Delta S_{\mathrm{diss}}^{\mathrm{o}}-\Delta C_{\mathrm{p}, \text { diss }}}{R}-\frac{\Delta H_{\mathrm{diss}}^{\mathrm{o}}-T_{\mathrm{o}} \Delta C_{\mathrm{p}, \text { diss }}}{R T} \\
& +\frac{\Delta C_{\mathrm{p}, \mathrm{diss}}}{R} \ln \left(\frac{T}{T_{\mathrm{o}}}\right)
\end{aligned}
$$

where $T_{0}=298.15 \mathrm{~K}$. With data from the sources described above, this becomes

$$
\ln \left(K_{\mathrm{p}}\right)=118.87-\frac{24084}{T}-6.025 \ln (T) .
$$

The dissociation constants calculated from Equation (16) should be accurate to within $\pm 12 \%$. This equation predicts dissociation constants that are about $50 \%$ larger than those predicted by the equation of Stelson and Seinfeld (1982).

To obtain the temperature dependence of $K_{\mathrm{p}}^{*}$ (Equation 8), we first note that the temperature dependence of $K_{\mathrm{zp}}$ is given by

$$
\begin{aligned}
\ln \left(K_{\mathrm{sp}}\right)= & \frac{\Delta S_{\mathrm{soln}}^{\mathrm{o}}-\Delta C_{\mathrm{p}, \text { soln }}}{R}-\frac{\Delta H_{\mathrm{soln}}^{\mathrm{o}}-T_{\mathrm{o}} \Delta C_{\mathrm{p}, \text { soln }}}{R T} \\
& +\frac{\Delta C_{\mathrm{p}, \text { soln }}}{R} \ln \left(\frac{T}{T_{\mathrm{o}}}\right)
\end{aligned}
$$

where $\Delta S_{\mathrm{soln}}^{\circ}, \Delta H_{\mathrm{soln}}^{\circ}$ and $\Delta C_{\mathrm{p}, \text { soln }}$ are for the process of passing from the solid to the solution in its standard state (infinite dilution). The standard free energy of solution is determined from

$$
\Delta G_{\mathrm{soln}}^{\mathrm{o}}=-2 R T_{\mathrm{o}} \ln \left(\gamma_{ \pm, \mathrm{sat}} m_{\mathrm{sat}}\right) .
$$

Using the data of Wishaw and Stokes (1953) for the saturated solution, $\Delta G_{\mathrm{soln}}^{\mathrm{o}}=-6.09 \mathrm{~kJ} \mathrm{~mol}^{-1}$. From Vanderzee et al. $(1980 \mathrm{~b}), \Delta H_{\mathrm{soln}}^{0}=25.54 \mathrm{~kJ} \mathrm{~mol}^{-1}$. Stelson and Seinfeld (1982) give an equation for the partial molal heat capacities; evaluating this at $m=0$ and combining the result with the data cited above for the gas-phase species yields $\Delta C_{\mathrm{p}, \text { soln }}^{\mathrm{o}} / R=11.208$.

The temperature dependence of the activity coefficients is given by (Lewis et al., 1961, p. 392):

$$
\begin{aligned}
\ln \left(\gamma_{ \pm}^{2}\right)= & \ln \left(\gamma_{ \pm, 0}^{2}\right)-\frac{\bar{L}_{\mathrm{o}}}{R T_{\mathrm{o}}}+\frac{\bar{J}}{R}+\frac{\bar{L}_{\mathrm{o}}-\bar{J} T_{\mathrm{o}}}{R T} \\
& -\frac{\bar{J}}{R} \ln \left(\frac{T}{T_{\mathrm{o}}}\right),
\end{aligned}
$$

where $\gamma_{ \pm}$is the mean activity coefficient, $\bar{L}_{\mathrm{o}}$ is the relative partial molal enthalpy, and $\bar{J}$ is the relative partial molal heat capacity. Subscript $o$ indicates the value at $T=T_{0}$. These quantities are for the solute at a fixed molality $m$ and $298 \mathrm{~K}$. Note that Equation (19) applies to $\gamma_{ \pm}^{2}$ since it is this quantity, and not $\gamma_{ \pm}$, that is proportional to the activity of $\mathrm{NH}_{4} \mathrm{NO}_{3}(\mathrm{aq})$. The corresponding equation given by Stelson and Seinfeld (1982) is incorrect in this respect.

Equations (17), (19) and (15) may be substituted into Equation (8) to give

$$
\begin{aligned}
\ln \left(K_{\mathrm{p}}^{*}\right)= & \frac{\Delta S_{\mathrm{m}}^{\circ}-\Delta C_{\mathrm{p}, \mathrm{m}}}{R}-\frac{\Delta H_{\mathrm{m}}^{\circ}-T_{\mathrm{o}} \Delta C_{\mathrm{p}, \mathrm{m}}}{R T} \\
& +\frac{\Delta C_{\mathrm{p}, \mathrm{m}}}{R} \ln \left(\frac{T}{T_{\mathrm{o}}}\right)
\end{aligned}
$$

where

$$
\begin{gathered}
\Delta S_{\mathrm{m}}^{\circ}=\Delta S_{\mathrm{diss}}^{\mathrm{o}}-\Delta S_{\mathrm{soln}}^{\mathrm{o}}+2 R \ln \left(\gamma_{ \pm, \mathrm{o}} m\right)-\frac{\bar{J}}{T_{\mathrm{o}}} \\
\Delta H_{\mathrm{m}}^{\mathrm{o}}=\Delta H_{\mathrm{diss}}^{\mathrm{o}}-\Delta H_{\mathrm{soln}}^{\mathrm{o}}-\frac{\bar{L}_{\mathrm{o}}}{R}
\end{gathered}
$$

and

$$
\Delta C_{\mathrm{p}, \mathrm{m}}=\Delta C_{\mathrm{p}, \mathrm{diss}}-\Delta C_{\mathrm{p}, \mathrm{soln}}-\bar{J} .
$$

These quantities are for the evaporation of equal amounts of $\mathrm{NH}_{3}(\mathrm{~g})$ and $\mathrm{HNO}_{3}(\mathrm{~g})$ from a solution with the specified molality, $m$.

Hamer and Wu (1972) have fit the data of Wishaw and Stokes (1953) to obtain an analytic expression for $\gamma_{ \pm .0}$ as a function of $m$. Stelson and Seinfeld (1982) have provided expansions, in half powers of $m$, for $\bar{L}_{\mathrm{o}}$ and $\bar{J}$ based upon the data of Vanderzee $e t$ al. (1980a) and Roux et al. (1978). These expressions were used (with a small modification as described in the 
Table 3. Expansion coefficients for Equations (24) and (26)

\begin{tabular}{lccc}
\hline$i$ & $a_{i}$ & $b_{i}$ & $c_{i}$ \\
\hline 0 & -9.293 & 15876 & 11.208 \\
1 & 33.983 & 1259.4 & -5.223 \\
2 & 45.4557 & 2867.7 & -6.318 \\
3 & -28.5816 & -1704.56 & 4.013 \\
4 & 5.9599 & 378.94 & -0.822 \\
5 & -0.44257 & -36.144 & 0.0564 \\
6 & 0.003962 & 1.2071 & 0.0 \\
\hline
\end{tabular}

following) in Equation (20) to obtain

$$
\begin{aligned}
\ln \left(K_{\mathrm{p}}^{*}\right)= & 2 \ln (m)-\frac{2.3523 \sqrt{m}}{1+0.925 \sqrt{m}} \\
& +\sum_{i=0}^{6}\left[a_{i}-\frac{b_{i}}{T}+c_{i} \ln T\right] m^{i / 2} .
\end{aligned}
$$

The coefficients for Equation (24), with $K_{\mathrm{p}}^{*}$ in $\mathrm{nb}^{2}$, are given in Table 3. Equation (24) may also be applied to an ideal solution by dropping the Debye-Huckel term (the 2 nd term on the right-hand side) and setting all the expansion coefficients for $i>0$ equal to zero.

The relative humidity at which a solution of a given molality is in equilibrium with water vapour is given by the water activity. The water activity, $a_{w}$, at any temperature, $T$, may be related to the activity, $a_{w,}$, for a solution of the same composition at $T_{0}=298.15 \mathrm{~K}$ by the equation

$$
\begin{aligned}
\ln \left(a_{\mathrm{w}}\right)= & \ln \left(a_{\mathrm{w}, \mathrm{o}}\right)-\frac{\bar{L}_{\mathrm{w}}-\bar{C}_{\mathrm{p}, \mathrm{w}} T_{\mathrm{o}}}{R}\left[\frac{1}{T_{\mathrm{o}}}-\frac{1}{T}\right] \\
& -\frac{\bar{C}_{\mathrm{p}, \mathrm{w}}}{R} \ln \left[\frac{T}{T_{\mathrm{o}}}\right] .
\end{aligned}
$$

The partial molal enthalpy, $\bar{L}_{\mathrm{w}}$, and heat capacity, $\bar{C}_{\mathrm{p}, \mathrm{w}}$, for water may be obtained from those of the solute by use of the Gibbs-Duhem equation. This gives us, for the osmotic coefficient, $\phi$,

$$
\begin{aligned}
\phi= & 1-\frac{1.4861}{m}\left[D-2 \ln D-\frac{1}{D}\right]+\sum_{i=1}^{6} \frac{i}{2(i+2)} \\
& \times\left[a_{i}-\frac{b_{i}}{T}+c_{i} \ln T\right] m^{i / 2},
\end{aligned}
$$

where

$$
D=1+0.925 \sqrt{m}
$$

and

$$
\ln \left(a_{w}\right)=\frac{-2 m \phi}{55.51} .
$$

The coefficients for Equation (26) are the same as for Equation (24) and are given in Table 3.

Equations (24) and (26) allow the calculation of $K_{p}^{*}$ and $a_{w}$ as functions of composition and temperature. Together, they provide an implicit equation for $K_{p}^{*}$ as a function of temperature and relative humidity. The validity of these equations can be tested as follows. Linke and Seidel (1965) provide data on the solubility of $\mathrm{NH}_{4} \mathrm{NO}_{3}$ in water as a function of temperature. Over the temperature range for which the solid is in phase IV, these data can be fit by the expression

$$
\ln \left(m_{\mathrm{sat}}\right)=9.771-\frac{1935}{T} .
$$

Equations (24) and (26) can be used to evaluate $K_{\mathrm{p}, \text { sat }}^{*}$ and $a_{\mathrm{w}, \text { sat }}$ (i.e. the relative humidity at the deliquescence point) along this saturation line. Figure 2a shows the ratio of the resulting values of $K_{\mathrm{p} \text {, sat }}^{*}$ to the value of $K_{\mathrm{p}}$ evaluated for the solid using Equation (16). Figure $2 \mathrm{~b}$ compares the calculated values of $a_{\mathrm{w}, \mathrm{sat}}$ to the experimental points of Dingemans (1941) from 10 to $32^{\circ} \mathrm{C}$ and the value determined by Wishaw and Stokes $(1953)$ at $25^{\circ} \mathrm{C}$. This later value should be more reliable since it was determined by the isopiestic method rather than by measurement of the total vapour pressure. Although the calculated values of $a_{\mathrm{w}, \mathrm{sat}}$ are systematically larger (by $1-2 \%$ ) than the data of Dingemans, they agree well with the value of Wishaw and Stokes. The calculated values may be
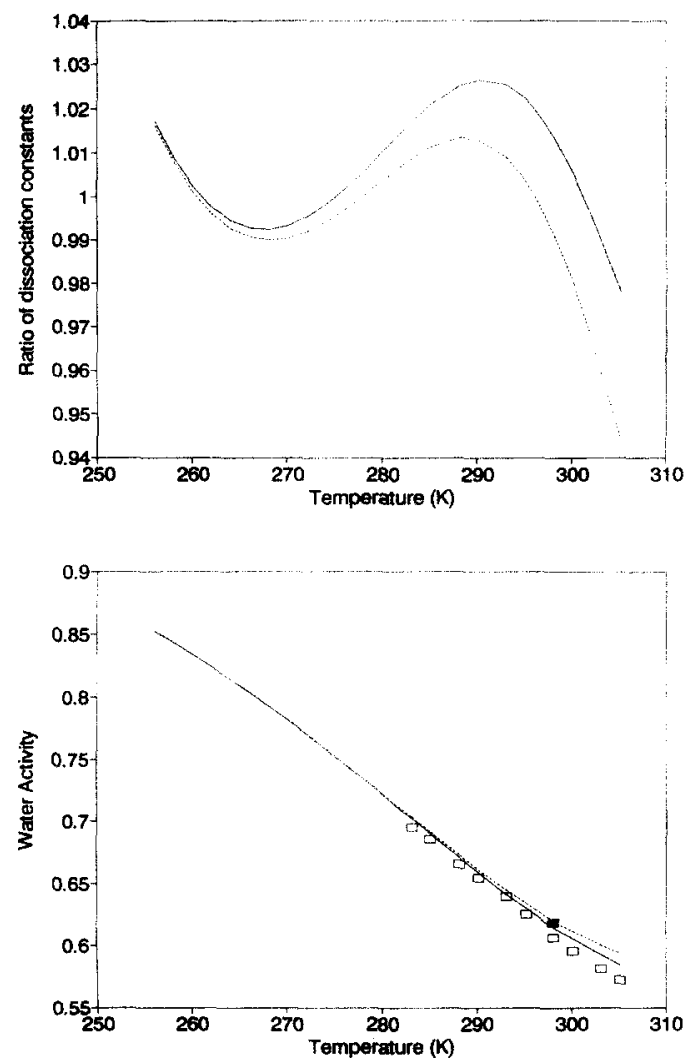

Fig. 2. (a) Ratio of $K_{\mathrm{p}}^{*}$ for the saturated solution to $\boldsymbol{K}_{\mathrm{p}}$ for the solid as a function of temperature. (b) Comparison of calculated and measured water activities for saturated solutions. $\square$ Data of Dingemans (1941), data of Wishaw and Stokes (1953). (a, b) - - - calculated using the parameters given by Hamer and Wu (1972); using slightly modified parameters (see text). 
represented to within $2 \%$ by the equation

$$
\ln \left(a_{\mathrm{w}, \mathrm{sat}}\right)=-2.551+\frac{618.3}{T} .
$$

This equation differs significantly from those given by Stelson and Seinfeld (1982) and Wexler and Seinfeld (1991) except at temperatures near $25^{\circ} \mathrm{C}$.

The broken lines in Fig. 2 were calculated using the parameters given by Hamer and Wu (1972). It can be seen that the results begin to deviate rapidly above $298 \mathrm{~K}$. This is not surprising. The parameters were based on a fit of data up to saturation ( 25.95 molal) at $25^{\circ} \mathrm{C}$. Calculations on the saturated solutions at higher temperatures require an extrapolation (to 31 molal at $32^{\circ} \mathrm{C}$ ) of an equation that has no physical basis. In fact, the calculated activity coefficients of Hamer and $\mathrm{Wu}$ (1972) begin to diverge from the experimental values (Wishaw and Stokes, 1953) above 24 molal. Accordingly, the coefficient of the cubic term in the equation given by Hamer and $\mathrm{Wu}(1972)$ was adjusted from $-1.9075 \times 10^{-5}$ to $-1.8814 \times 10^{-5}$. This amounts to using the solubility data to determine the activity coefficients above 27 molal and results in the solid lines in Fig. 2. The coefficients in Table 3 are based on this adjusted parameter. The smoothly varying nature of the remaining deviations is probably due to the deficiencies of using a polynomial to fit the data; the remaining errors $( \pm 2 \%)$ are within the uncertainty of the measurements. The agreement between the results for the saturated solutions and the solid may also be seen in Fig. 3. This is in contrast to the results of Stelson and Seinfeld (1982) who found large discrepancies between $K_{\mathrm{p}}$ and $K_{\mathrm{p}}^{*}$ for the saturated solution.

Although the extrapolation of the modified equation of Hamer and $\mathrm{Wu}$ gives good results up to saturation at temperatures up to $32^{\circ} \mathrm{C}$, at lower temperatures the calculated value of $K_{p}^{*}$ passes through

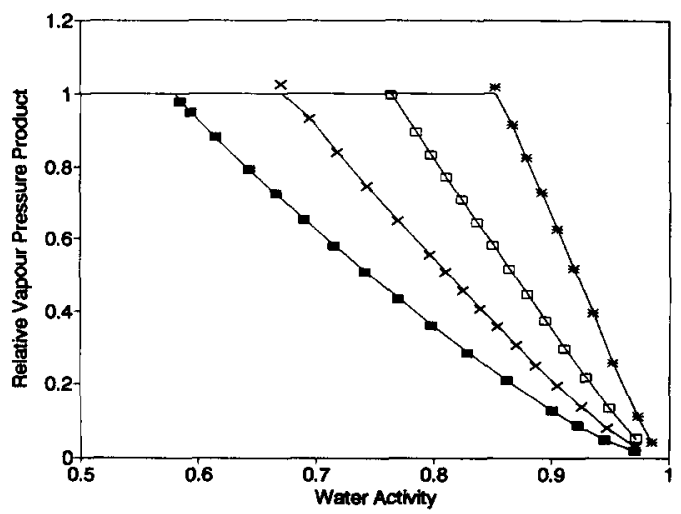

Fig. 3. Temperature and relative humidity dependence of the equilibrium vapour pressure product, $K_{p}^{*}$. Values are plotted relative to the dissociation constant, $K_{\mathrm{p}}$, of the solid. Points are calculated from Equations (24) and (26); * $-17^{\circ} \mathrm{C}, \square 0^{\circ} \mathrm{C}, \times 15^{\circ} \mathrm{C}, 32^{\circ} \mathrm{C}$. The lines are calculated from Equation (34). a maximum at a concentration somewhat above saturation. Thus, these equations are not suitable for supersaturated solutions.

The values used for $\bar{L}_{0}$ and $\bar{J}$ (and therefore also for $\bar{L}_{\mathrm{w}}$ and $\bar{C}_{\mathrm{p}, \mathrm{w}}$ ) above 25 molal were also based on extrapolations of data from lower concentrations. However, since these high concentrations will only occur for temperatures near $25^{\circ} \mathrm{C}$, these terms will have relatively little effect. An error of $1 \mathrm{~kJ} \mathrm{~mol}^{-1}$ in $\bar{L}_{\mathrm{o}}$ or $\bar{L}_{\mathrm{w}}$ will only change $K_{\mathrm{p}}^{*}$ or $a_{\mathrm{w}}$ by $1 \%$ at $32^{\circ} \mathrm{C}$. Since these parameters only change by only 5.1 and $2.6 \mathrm{~kJ} \mathrm{~mol}^{-1}$, respectively, over the range of the extrapolation the errors should not be more than 1 or $2 \%$. The effect of errors in partial molal heat capacities are negligible over such a small temperature range.

These equations may also be tested by applying them to very dilute (ideal) solutions. In this case, we obtain from Equations (7) and (24), with $\gamma_{ \pm}=1$ :

$$
\begin{gathered}
\frac{K_{2}\left(\mathrm{NH}_{4}^{+}\right)}{K_{\mathrm{a}}\left(\mathrm{HNO}_{3}\right) H\left(\mathrm{HNO}_{3}\right) H\left(\mathrm{NH}_{3}\right)} \\
=\exp \left[a_{0}-\frac{b_{0}}{T}+c_{0}\right] .
\end{gathered}
$$

The ratio of the left-hand to the right-hand side may now be evaluated as a function of temperature; the results are shown in Fig. 4. For the product $K_{\mathrm{a}}\left(\mathrm{HNO}_{3}\right) \mathrm{H}\left(\mathrm{HNO}_{3}\right)$ the equation of Clegg and Brimblecombe (1990) was used. For $K_{\mathbf{a}}\left(\mathrm{NH}_{3}\right)$ the data of Bates and Pinching (1950) may be fit to $0.2 \%$ by

$$
\ln \left(K_{\mathrm{NH}_{4}^{+}}\right)=-0.227-\frac{6279}{T} .
$$

Although these data are for the temperature range $0-50^{\circ} \mathrm{C}$, the quality of the data and the fit are such that a value of $\Delta C_{\mathrm{p}}$ greater than $R$ can be excluded. The error in the extrapolation to $256 \mathrm{~K}$ should then

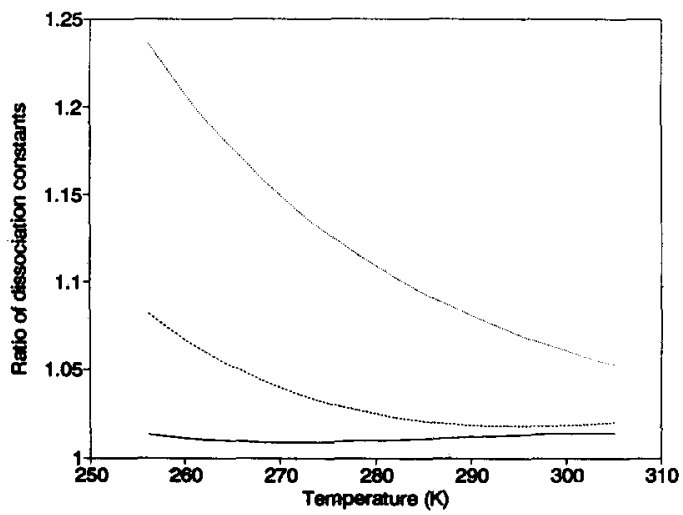

Fig. 4. The ratio of $K^{*}$ calculated from Equation (7) to that from Equation (24) for ideal solutions. The various curves are for the temperature dependence of the Henry's law constant for $\mathrm{NH}_{3}$ calculated from the data of Dasgupta and Dong (1986) (. . .), Vanderzee and King (1972) with $\Delta C_{\mathrm{p}}=0(---)$, and Vanderzee and King (1972) with $\Delta C_{\mathrm{p}}=5 R(-)$. 
be no more than $2 \%$. When the expression given by Dasgupta and Dong (1986) is used for the temperature dependence of $\mathrm{H}\left(\mathrm{NH}_{3}\right)$, the dotted line in Fig. 4 results. Since this equation is based on a fit of data over a limited temperature range and the data were only fit to an accuracy of a few per cent, it should not be surprising if it should result in relatively large errors in an extrapolation. Vanderzee and King (1972) give values of $\Delta H^{\circ}$ and $\Delta G^{\circ}$ for Reaction (14) but $\Delta C_{p}$ does not seem to have been measured for this reaction. Using this data and setting $\Delta C_{p}$ equal to zero results in the dashed line in Fig. 4. Setting $\Delta C_{\mathrm{p}}$ equal to $5 R$ (the value for $\mathrm{H}_{2} \mathrm{O}(\mathrm{g}) \rightarrow \mathrm{H}_{2} \mathrm{O}(\mathrm{l})$ ) yields

$$
\ln \left(H\left(\mathrm{NH}_{3}\right)\right)=-43.70+\frac{5746}{T}+5 \ln (T)
$$

and results in the solid line in Fig. 4. It is clear that the temperature dependencies are consistent to within the uncertainty of the thermodynamic parameters for $\mathbf{R e}$ action (14).

Having established the validity of these equations, we may now use them to determine the temperature and relative humidity dependence of $K_{p}^{*}$. Equations (24) and (26) may be used to calculate both $K_{p}^{*}$ and $a_{w}$ as functions of molality and temperature. The results of such a calculation were used to generate the points in Fig. 3. The solid lines in Fig. 3 were calculated from the equation

$$
\begin{aligned}
K_{\mathrm{p}}^{*}= & \left(P_{1}-P_{2}\left(1-a_{\mathrm{w}}\right)+P_{3}\left(1-a_{\mathrm{w}}\right)^{2}\right) \\
& \times\left(1-a_{\mathrm{w}}\right)^{1.75} K_{\mathrm{p}}
\end{aligned}
$$

where

$$
\begin{aligned}
& \ln \left(P_{1}\right)=-135.94+\frac{8763}{T}+19.12 \ln (T) \\
& \ln \left(P_{2}\right)=-122.65+\frac{9969}{T}+16.22 \ln (T)
\end{aligned}
$$

and

$$
\ln \left(P_{3}\right)=-182.61+\frac{13875}{T}+24.46 \ln (T) .
$$

These smooth curves fit the calculated points to within $1 \%$ for relative humidities less than $94 \%$ (concentrations greater than 2.5 molal) and to within $4 \%$ for r.h. $<99.7 \%$ ( $>0.1$ molal). Equation (34) is not consistent with the Debye-Huckel equation and so does not provide accurate results for dilute solutions.

\section{DEPENDENCE OF DISSOCIATION CONSTANT AND DELIQUESCENCE POINT ON PARTICLE SIzE}

As the size of a particle of solid $\mathrm{NH}_{4} \mathrm{NO}_{3}$ becomes smaller, the value of $K_{\mathrm{p}}$ will increase because of the Kelvin effect according to the formula (Lewis et al., 1961, p. 483):

$$
K_{\mathrm{p}}(a)=K_{\mathrm{p}}(\mathrm{bulk}) \exp \left(\frac{2 \sigma \bar{v}}{a R T}\right),
$$

where $\sigma$ is the surface tension of the particle, $\bar{v}$ is the molar volume of $\mathrm{NH}_{4} \mathrm{NO}_{3}, a$ is the particle radius (i.e. the radius of a sphere with the same volume as the particle), $R$ is the gas constant and $T$ is the absolute temperature. At $25^{\circ} \mathrm{C}, \sigma=113$ dynes $\mathrm{cm}^{-1}$ (Kodas et al., 1986) and $\bar{v}=46.5 \mathrm{~cm}^{3} \mathrm{~mol}^{-1}$ (Mellor, 1964, p. 518 ), so $K_{\mathrm{p}}(a)$ is $4.3 \%$ larger than the bulk value for a particle radius of $0.1 \mu \mathrm{m}$ and $53 \%$ larger for $a=0.01 \mu \mathrm{m}$.

This decrease in the stability of the solid will also increase its solubility. This will be partially offset by the fact that $K_{\mathrm{p}}^{*}$ for the solution droplet will increase in the same manner as $K_{\mathrm{p}}$. In this case the surface tension and radius of the solution drop and the partial molal volume of $\mathrm{NH}_{4} \mathrm{NO}_{3}(\mathrm{aq})$ must be used in Equation (38). The surface tension of the solution as a function of concentration is given in the International Critical Tables (Washburn, 1928, vol. 4, p. 464). The difference, $\Delta \sigma$, between the surface tension on the solution and that of pure water is independent of temperature and may be fit by

$$
\Delta \sigma=\frac{m}{1+0.034 m}
$$

which is of the general form suggested by Eberhart (1966). The data for the density of the solution (Mellor, 1964, p. 520) may be fit by assuming a constant partial molal volume of $51.2 \mathrm{~cm}^{2} \mathrm{~mol}^{-1}$ for $\mathrm{NH}_{4} \mathrm{NO}_{3}(\mathrm{aq})$. This also implies that the partial molal volume of $\mathrm{H}_{2} \mathrm{O}$ is constant at $18.07 \mathrm{~cm}^{3} \mathrm{~mol}^{-1}$, the same as for pure water. Using this data, the solution drop size and the value of $K_{\mathrm{p}}^{*}$ may be calculated as a function of concentration; the saturated solution will be the one for which $K_{\mathrm{p}}^{*}=K_{\mathrm{p}}$. This calculation requires extrapolating the activity coefficients to concentrations that are supersaturated with respect to the bulk. As noted previously, the equation of Hamer and Wu (1972) is not suitable for this purpose. However, for concentrations above 20 molal, the osmotic coefficient varies linearly with molality (Wishaw and Stokes, 1953). This linear behaviour was assumed to continue for supersaturated conditions and thus the activity coefficients from the Gibbs-Duhem equation were determined. An iterative solution of the equation $K_{\mathrm{p}}^{*}=K_{\mathrm{p}}$ then reveals that the solubility (at $25^{\circ} \mathrm{C}$ ) increases to 26.5 molal for a dry particle radius of $0.1 \mu \mathrm{m}$ and $31.3 \mathrm{molal}$ for $a=0.01 \mu \mathrm{m}$. The ratio of the radius of the saturated solution drop to that of the dry particle decreases from 1.246 to 1.215 over this same range.

Finally, the deliquescence point of the salt will also be affected by particle size. There are two opposing effects here. First, the vapour pressure of water will be decreased because of the increase in solute concentration at saturation. Second, the vapour pressure will increase because of the Kelvin effect, Equation (38). The result is that particle size has little effect on the deliquescence point. The deliquescence point for a dry particle of $0.1 \mu \mathrm{m}$ radius is $62.0 \%$ and is $63.7 \%$ for 
a radius of $0.01 \mu \mathrm{m}$. Thus the only significant effect of particle size will be to increase the value of $K_{\mathrm{p}}$ and this will only be substantial for radii below $0.1 \mu \mathrm{m}$. Although the surface tensions of the solid and of the solutions are not very well known, these conclusions are not very sensitive to the exact values used.

\section{CONCLUSIONS}

Thermodynamic data relevant to the system $\mathrm{NH}_{4} \mathrm{NO}_{3} / \mathrm{NH}_{3} / \mathrm{HNO}_{3}$ from a variety of sources have been examined. These include calorimetric data, measurements of the vapour pressure of the solid and liquid, data on dilute solutions of $\mathrm{NH}_{3}(\mathrm{aq})$ and $\mathrm{HNO}_{3}(\mathrm{aq})$, isopiestic and thermal data on aqueous solutions of varying concentration, and data on the concentrations and vapour pressures of saturated solutions. The data are found to be highly consistent and are sufficient to determine the dissociation constant of solid and aqueous $\mathrm{NH}_{4} \mathrm{NO}_{3}$ as a function of temperature and relative humidity with errors of $15 \%$ or less. The results may be expressed in terms of reasonably convenient equations. The dissociation constants are significantly increased when particle radii are less than $0.1 \mu \mathrm{m}$. More accurate data on the temperature dependence of the Henry's law constant for $\mathrm{NH}_{3}$ would be helpful in fully accessing the accuracy of this equation.

The results obtained here are similar to those obtained by Stelson and Seinfeld (1982), although the recommended value of $K_{\mathrm{p}}$ is about $50 \%$ larger. However, their analysis suggests that there are larger discrepancies both between values of the dissociation constant of the solid as obtained from various sources and between the dissociation constant of solid $\mathrm{NH}_{4} \mathrm{NO}_{3}$ and saturated solutions of $\mathrm{NH}_{4} \mathrm{NO}_{3}$. The present analysis shows that those discrepancies are not inherent in the data.

Acknowledgement-This work was supported by a grant from the Atmospheric Environment Service and the Natural Sciences and Engineering Research Council of Canada.

\section{REFERENCES}

Allen A. G., Harrison R. M. and Erisman J. (1989) Field measurements of the dissociation of ammonium nitrate and ammonium chloride aerosols. Atmospheric Environment 23, 1591-1599.

Bates R. G. and Pinching G. D. (1950) Dissociation constant of aqueous ammonia at 0 to $50^{\circ}$ from e.m.f. studies of the ammonium salt of a weak acid. J. Am. Chem. Soc. 72, 1393-1396.

Brander J. D., Junk N. M., Lawrence J. W. and Robins J. (1962) Vapor pressure of ammonium nitrate. J. Chem. Engng Data 7, 227-228.

Brost R. A., Delaney A. C. and Huebert B. J. (1988) Numerical modeling of concentrations and fluxes of $\mathrm{HNO}_{3}$, $\mathrm{NH}_{3}$, and $\mathrm{NH}_{4} \mathrm{NO}_{3}$ near the surface. J. geophys. Res. 93 , 7137-7152.

Chase M. W., Davies C. A., Downey J. R., Frurip D. J.,
McDonald R. A. and Syverud A. N. (1985) JANAF Thermochemical Tables, 3rd edn. National Bureau of Standards, Washington, DC.

Clegg S. L. and Brimblecombe P. (1990) Equilibrium partial pressures and mean activity and osmotic coefficients of $0-100 \%$ nitric acid as a function of temperature. J. phys. Chem. 94, 5369-5380.

Cox J. D., Harrop D. and Head A. J. (1979) The standard enthalpy of formation of ammonium nitrate and the nitrate ion. J. Chem. Thermodyn. 11, 811-814.

Cox J. D., Wagman D. D. and Medvedev V. A. (1989) CODATA Key Values for Thermodynamics. Hemisphere, New York.

Dasgupta P. K. and Dong S. (1986) Solubility of ammonia in liquid water and generation of trace levels of standard gaseous ammonia. Atmospheric Environment 20, 565-570.

Dellien I. (1982) A DSC study of the phase transitions of ammonium nitrate. Thermochim. Acta 55, 181-191.

Dingemans P. (1941) Die Dampfspannung von gesättigen $\mathrm{NH}_{4} \mathrm{NO}_{3}$-lösungen. Rec. Trav. Chim. 60, 317-328.

Dionne B. C., Rounbehier D. P., Achter E. K., Hobbs J. R. and Fine D. H. (1986) Vapor pressure of explosives. $J$. Energet. Mater. 4, 447-472.

Durham J. L., Spiller L. L. and Ellestad T. G. (1987) Nitric acid-nitrate aerosol measurements by a diffusion denuder: a performance evaluation. Atmospheric Environment 21, 589-598.

Eberhart J. G. (1966) The surface tension of binary liquid mixtures. J. phys. Chem. 70, 1183-1186.

Eichenauer W. and Liebscher D. (1965) Die Molwarme des Ammoniumnitrats zwischen 11 und $280^{\circ} \mathrm{K}$. Z. Natur. forsch. 20a, 160-161.

Feick G. (1954) The dissociation pressure and free energy of formation of ammonium nitrate. J. Am. Chem. Soc. 76, 5858-5860.

Forsythe W. R. and Giauque W. F. (1942) The entropies of nitric acid and its mono- and tri-hydrates. Their heat capacities from 15 to $300^{\circ} \mathrm{K}$. The heats of dilution at $298.1^{\circ} \mathrm{K}$. The internal rotation and free energy of nitric acid gas. The partial pressures over its aqueous solutions. J. Am. Chem. Soc. 64, 48-61.

Haar L. (1968) Thermodynamic properties of ammonia as an ideal gas. J. Res. Natn. Bureau Stand. 72A, 207-216.

Hamer W. J. and Wu Y.-C. (1972) Osmotic coefficients and mean activity coefficients of uni-univalent electrolytes in water at $25^{\circ} \mathrm{C}$. J. Phys. Chem. Ref. Data 1, 1047-1099.

Harrison R. M., and MacKenzie A. R. (1990) A numerical simulation of kinetic constraints upon achievement of the ammonium nitrate dissociation equilibrium in the troposphere. Atmospheric Environment 24A, 1883-1888.

Harrison R. M., Sturges W. T., Kitto A.-M. N. and Li Y. (1990) Kinetics of evaporation of ammonium chloride and ammonium nitrate aerosols. Atmospheric Environment 24A, 91-102.

Huebert B. J., Luke W. T., Delaney A. C. and Brost R. A. (1988) Measurements of concentrations and dry surface fluxes of atmospheric nitrates in the presence of ammonia. J. geophys. Res. 93, 7127-7136.

Jaffe D. A. (1988) Accuracy of measured ammonium nitrate equilibrium values. Atmospheric Environment 22, 23292330.

Kodas T. T., Pratsinis S. E. and Friedlander S. K. (1986) Aerosol formation and growth in a laminar core reactor. J. Colloid Interf. Sci. 111, 102-111.

de Kruif C. G. (1982) The vapor phase dissociation of ammonium salts: ammonium halides, ammonium rhodanide, ammonium nitrate, and ammonium bicarbonate. J. chem. Phys. 77, 6247-6250.

Lewis G. N., Randall M., Pitzer K. S. and Brewer L. (1961) Thermodynamics, 2nd edn. McGraw-Hill, New York.

Linke W. F. and Seidell A. S. (1965) Solubilities of Inorganic and Metal-Organic Compounds, 4th edn, Vol. II, p. 709. American Chemical Society, Washington, DC. 
Mellor J. W. (1964) A Comprehensive Treatise on Inorganic and Theoretical Chemistry, Vol. 8, Suppl. 1. Longmans, London.

Nagatani M., Seiyama T., Sakiyama M., Suga H. and Seki S (1967) Heat capacities and thermodynamic properties of ammonium nitrate crystal: phase transitions between stable and metastable phases. Bull. Chem. Soc. Japan 40, 1833-1844.

Pitzer K. S. (1937) The heats of ionization of water, ammonium hydroxide, carbonic, phosphoric, and sulfuric acids. The variation of ionization constants with temperature and the entropy change with ionization. $J$. Am. Chem. Soc. 59, 2365-2371.

Roux A., Musbally G. M., Perron G., Desnoyers J. E., Singh P. P., Woolley E. M. and Hepler L. G. (1978) Apparent molal heat capacities and volumes of aqueous electrolytes at $25^{\circ} \mathrm{C}: \mathrm{NaClO}_{3}, \mathrm{NaClO}_{4}, \mathrm{NaNO}_{3}, \mathrm{NaBrO}_{3}, \mathrm{NaIO}_{3}$, $\mathrm{KClO}_{3}, \quad \mathrm{KBrO}_{3}, \quad \mathrm{KIO}_{3}, \quad \mathrm{NH}_{4} \mathrm{NO}_{3}, \mathrm{NH}_{4} \mathrm{Cl}$, and $\mathrm{NH}_{4} \mathrm{ClO}_{4}$. Can. J. Chem. 56, 24-28.

Stelson A. W. and Seinfeld J. H. (1982) Relative humidity and temperature dependence of the ammonium nitrate dissociation constant. Atmospheric Environment 16, 983-992.

Stelson A. W., Friedlander S. K. and Seinfeld J. H. (1979) A note on the equilibrium relationship between ammonia and nitric acid and particulate ammonium nitrate. Atmospheric Environment 13, 369-371.

Stephenson C. C., Benz D. R. and Stevenson D. A. (1955) The heat capacity of ammonium nitrate from 15 to $315^{\circ} \mathrm{K} . J$. Am. Chem. Soc. 77, 2161-2164.

Tang I. N., Munkelwitz H. R. and Lee J. H. (1988) Vapor-liquid equilibrium measurements for dilute nitric acid solutions. Atmospheric Environment 22, 2579-2585.

Vanderzee C. E. and King D. L. (1972) The enthalpies of solution and formation of ammonia. J. Chem. Thermodyn. $4,675-683$.

Vanderzee C. E., King D. L. and Wadso I. (1972) The enthalpy of ionization of aqueous ammonia. J. Chem. Thermodyn. 4, 685-689.

Vanderzee C. E., Waugh D. H. and Haas N. C. (1980a) Enthalpies of dilution and relative apparent molar enthalpies of aqueous ammonium nitrate. The case of a weakly hydrolyzed (dissociated) salt. J. Chem. Thermodyn. 12, 21-25.

Vanderzee C. E., Waugh D. H., Haas N. C. and Wigg D. A. (1980b) The standard enthalpy of solution of $\mathrm{NH}_{4} \mathrm{NO}_{3}(\mathrm{c}$, IV) in water at $298.15 \mathrm{~K}$. (A search for the standard thermodynamic state.) J. Chem. Thermodyn. 12, $27-40$.

Washburn E. W. (1928) International Critical Tables of Numerical Data, Physics, Chemistry and Technology. McGraw-Hill, New York.

Wexler A. S. and Seinfeld J. H. (1991) Second-generation inorganic aerosol model. Atmospheric Environment 25A, 2731-2748.

Wexler A. S. and Seinfeld J. H. (1992) Analysis of aerosol ammonium nitrate: departures from equilibrium during SCAQS. Atmospheric Environment 26A, 579-591.

Wishaw B. F. and Stokes R. H. (1953) The osmotic and activity coefficients of aqueous solutions of ammonium chloride and ammonium nitrate at $25^{\circ}$. Trans. Faraday Soc. 49, 27-31. 